it is an increased degree of the quality to preserve the balance of the body on a moving support, as on a cart in motion; but when the ever-varying and muscle-changing forces of which the motion of a horse at full gallop is the cause to Ducrow standing on the saddle, nay, of six horses at one and the same time, produce no perceptible change on the stead $y$, easy, and even graceful attitudes of the rider, the highest degree of the equilibrium-preserving power is attained." In Ducrow, the organ for weight, or more correctly for the application of mechanical force, is unusually large. It is likewise very large in a gentleman of my acquaintance, who, among other talents, possesses that of mechanics and engineering very remarkably. He assures me that he has great power of balancing his body; and when a boy, was the wonder of his companions for the chamois-like ease, and safety from wet feet, with which he skipped about from stone to stone in a shallow river.

The knowledge of resistance being acquired from gravitation and impenetrability, and of force from the instinct of muscular counter-resistance, the combined effect, probably as the result of experience, is much more extensive than the regulation of otr muscular movements. We can perceive the mechanical relations of external matter to external matter, and provide for our safety and increase our power by taking advantage of these relations. We find the different relative powers of resistance, called their density, in different kinds of matter, and availing ourselves of this knowledge, and exercising another faculty, namely, constructiveness, which manually fashions, forms, and constructs, we make tools and instruments ; hence we know and prize iron as the most valuable of metals, and form the axe, the chisel, the knife, and the saw. The mechanical powers, in their rudest state, are applied instinctively, in other words, under the impulse of the faculty in question.

A more extensive and accurate induction of facts than yet achieved is necessary for the localising of the organ of the faculty for counter-resisting resistance,-the application of force. Mr. Richard Edmonson, of Manchester, in two papers contributed to the "Phrenological Journal" (vol. vii., p. 106, and ix., p. 142), has endeavoured to show that the organ hitherto called construc. tiveness is that organ; and that what has been called weight, is " the perception of the position of objects relative to their centre of gravity," in other words, the perception of the direction of gravitation,-the perpendicular. The preponderance of evidence, however, is in favour of the organ called weight, from its being found invariably large in engineers and mechanicians, while constructiveness is not always found to be so. A standard for the vertical seems necessary to our safety, to our perceptiou of what we call up and down on revolving globes, and to the precis sion of all our movements; and a nice per. ception of it seems necessary to the just ap. plication of force : so that it is quite conceivable that the same faculty perceives the vertical, and applies force in its due degree. Mr. S. adduced many instances; but as he concluded that more evidence is called for, we shall not occupy space at present in detailing those instances.

In the discussion which followed Mr. Simpson's paper, no objections were stated to his conclusion, that man and animals have a sense for resistance and a faculty for applying force. Dr. Caldwell, of America, spoke at some length upon the subject, giving it as his opinion that that twofold truth had been demonstrated.

\section{REMUNERATION OF MEDICAL MEN IN THE UNIONS.}

\section{PROCEEDINGS AT BARNSTAPLE.}

\section{To the Editor of The Lancet.}

Sir :-As a reader of your liberal Periodical, The Lancet, I, of course, have noticed the occasional communications, conveyed through its pages, to the medical public, as well as some excellent remarks in your lead. ing article relative to the manner in which professional men are remunerated for their attendance on paupers, under the New Poorlaw Act; and it is in consequence of one such communication which I read last week that $I$ am induced to address you.

I have never had the honour to hold any appointment under the poor-law commissioners, but for twenty years previous to their assuming the "reins of government," I had the medical care of three large and populous parishes, and consequently must have had somelittle knowledge of the trouble and expense incurred by such a charge, and how inadequately the best paid medical men were remunerated for their time and for me. dicine supplied to the sick and suffering poor.

I cannot forget with what pleasure I lnoked forward (and, I believe, I stood not alone in my pleasing anticipations), when the projected alteration in the management of the paupers was talked of, because I hoped that such alteration would be a real amendment in every way, not only for the poor themselves, but also for those who had the charge of them; and in the latter were included the medical attendants. How far the former have been benefitted by the change, I will not stay here to inquire; but that the three "commanders-in-chief" are well provided for, there cannot, I think, be any doubt; nor does it appear that many of those who hold official situations under them are badly paid. Among the last-mentioned may be reckoned those members of the legal 
profession who fill the situation of secretaries to the different unions, all of whom appear to receive at least remunerating sa. laries.

But, ah! how sadly was I disappointed in finding out the way in which the medical profession were to be paid for that assistance which they, and they alone, can render, and which they are called upon to do at all times, and on all occasions, where their attendance is required. Why has it been thus, sir? Why have medical men been made a mark of? Surely the profession itself is one which ranks equally high with either of the other learned professions, and has attached to it all the moral responsibilities which they have, in an equal, if not, in some instances, even in a higher degree, and yet its members are so inefficiently paid for their services,services which must be had, which may not, cannot be dispensed with.

I take leave to ask you, sir, who are the parties most to be blamed? For, admitting that any man or set of men attempt to make a mark of, or to degrade in any way the members of the medical profession, either individually or collectively, are they, therefore, obliged to endure such treatment? Certainly not; and I think that, however much you and every other really liberal man must deprecate the system of medical remuneration under the present Poor-law Act, you will yet allow that medical men were at liberty, when they first understood the manner in, and rate at, which they were to be paid, to refuse tendering their professional aid under a fair remunerating price; and for such a paltry pittance, as it was too clearly intimated, would be doled out to them.

I am aware I may be told that these remarks come late in the day; but as it is never too late to amend the error of onr ways, so neither do I esteem it yet too late for our profession to make a determined stand against those well-paid commissioners who seem so much disposed to get their services for little or nothing, whilst themselves are enjoying the sweets of almost a princely income.

I have been led to make these general remarks from noticing a communication, as above stated, in The LANCET, relative to a particular branch of medical remunerationI allude to a letter addressed to you, sir, stating the pleasing fact, that in some provincial town fourteen (I believe) out of fifteen medical men had resolved not to vaccinate the paupers for less than two shillings and sixpence for each successful case. Such a resolution reflects honour on those who formed it. Similar instances may have occurred and been recorded in your valuable Publication, and have been overlooked by me, though I have noticed many. One such took place at Barnstaple, a few months ago, at which I was present; and it was my in- tention then to have sent you an account of the result of that meeting, but circumstances, which it would be useless now to state, prevented my doing so at the time.

At that meeting, not only did the medical men present pledge themselves not to vaccinate at less than half-a-crown for each successfol case, but with a spirit which ought to actuate every member of an honourable profession, took cognisance of an advertisement published by the Barnstaple board of guardians, in which that body had signifed their determination to discontinue a trifling per centage, which had before been allowed to district medical men on relief ordered by them, for out-door patients. This was considered to convey an irsinuation that the medical attendant might be induced to afford such relief merely for the sake of getting the said per centage, which, in all probability, would never amount to thirty shillings profit among all the medical men of the union, comprising twenty-nine parishes.

In accordance with the aforesaid pledge, it was " resolved" nem. con. that the substance of it should be forwarded to the Barnstaple Union, together with a recommendation to that body to give an order to all proper applicants to have their children vaccinated by their own medical man,* and to pay two-and-sixpence for each case; and at the same time an expostulatory address was sent to the board of guardians, stating that the above-mentioned advertisement contained an " insult by imputation to the members of the medical profession, and requesting them (the guardians of the poor) to withdraw it."

Now, sir, I think this meeting has bad a good effect, inasmuch as the lowest sum given, as far as I can ascertain, in this neighbourhood for vaccinating the poor, is half-acrown for each successful case; whereas, in some adjacent unions eighteenpence is offered as the maximum. Yes! one shilling and sixpence is liberally offered as a remunerating price, for doing that which cannot be well done, except by a person who has studied and practised vaccination professionally; for it is but too well known that many children have been vaccinated by old women, and others with a stocking needle, dipped in the vaccine virus at any but the proper time.

Could the immortal Jenner and many of his contemporaries and more immediate successors look up at this time, however much they might and would rejoice to see vaccination progressing rapidly, yet may we not venture to imagine that a great damp would be thrown on their joy when they saw the manner in which their followers were paid,

* Meaning that if labourers wished to have their children vaccinated by any regular qualified person instead of the " district surgeon" they might be permitted to do so. 
if paid it can be called, for rendering so great a blessing to their fellow-creatures.

I will again ask, is it not yet possible to make a determined stand against this humiliating, this very degrading rate of payment which the poor-law commissioners offer for services which surely deserve a higher reward, and which $\mathrm{m}$ ist ultimately be given if the members of the profession will, "one and all," act with due respect to their profession, and in common justice to themselves? I am well aware, that unless it was the "law of the land," that a fixed sum was established as the minimum charge, you cannot prevent any one from charging as little as he chooses; but I do think that among the members of the medical profession, to every individual of which the rank and title of a GENTLEMAN ought to be, and is (unless by his own base conduct he forfeits it), indelibly affixed, a law of honour, honesty, and liberality should exist; and that where any one acts in a manner derogatory to such principles, and, therefore, to the character of a gentleman, that then he should become a marked man, and his profession $a l$ brethren should express their disapprobation of his conduct by public expostulation and reproof.

If such were to be done, I really think that (unless such men were dead to every proper feeling) they would soon be made ashamed of their conduct, and their example might and would deter others from striking on the rock which they had split on. At the same time, I know too well that there are some lost to all proper feeling; and how to deal with such, I confess myself at a loss. It used to be said that there was a "black sheep in every flock," but such are now becoming very rare; and as regards the large flock of medical men, I trust that ere long none such will be seen or heard of.

I will not trespass longer on your time, or occupy more room in your pages, which, I am well aware, should be filed with matter of more importance; yet as it appears to me that every voice should be raised against the oppressive, grinding, and degrading system which the poor-law commissioners (and in too many instances, but not all, those under them) have adopted, and are pursuing towards our profession, I will venture to solicit the favour of your inserting this my mite of contribution at any time when you have a column to spare. I remair, Sir, your obedient servant,

W. Vellacott, Surgeon R.N.

Bracenton, Barnstaple, May 25, 1811.

TREATMENT OF DEFORMITIES OF THE KNEE.-KNOCK.KNEE.

To the Editor of THE LANCET.

SIr :-I beg to forward you the following cases of inward inclination of the knee, familiarly known by the name of " knockknee," treated by operation; and should you consider them of interest to the profession, I shall feel obliged by your giving them an early publication. I am, sir, your obedient servant,

R. W. Tamplin,
Surgeon to the Institution for the cure of Club-foot and other Contractions.

29, Great Queen-street, Lincoln's Inn-fields, J une 24, 1841.

Case 1.-H. G., æetat. 16, of delicate, unhealthy aspect, stated, when six years of age his feet were observed to incline out. wards, and his knees, in the act of progression, to knock together, which gradually increased and prevented his walking any distance without the greatest inconvenience. Six years since he experienced a pain on the inner side of each knee, which prevented his taking but a few steps withont resting. During the last eighteen months the deformity has rapidly increased; and in addition to the pains in the kuees he has also had pain in the ankle-joints, accompanied with a spasmodic action, or, as he himself terms it, a catching in the mnscles of the leg, which compelled him to rest for a quarter of an hour at a time.

The present appearance of this case, when the knees are placed parallel to each other is, that the feet are eighteen inches apart; and in consequence of the great deviation of the legs from the straight position, his feet have the appearance of the talipes varus deformity. His manner of walking was such as to give the impression of malformation of the bones; and this I imagined to be the case previous to an examination, for when asked to walk his knees rolled completely over one another. Having satisfied myself by a very careful examination that the deformity mainly depended upon contraction of the vastus externus, fascia lata, and biceps tendon, I proposed to his parents the following operation, as likely to remedy, if not cure, the deformity.

Dec. 3, 1840. Assisted by my friends, Messrs. Harvey, Garlike, and Berry, I divided the vastus externus and fascia lata of the right leg, which, after division, was found to have contracted upwards of two inches. The wound was retained by suture and bandage, but owing to slight hæmor. rhage, union by the first intention was prevented, and $I$ was in consequence unable to apply the splint for fourteen days. Extension was then commenced by means of a modified Dessault's splint, having a joint at the bend of the knee, acted upon by a male and female screw, the limb being retained in its position by means of straps attached to the splint through its entire length, the extension being daily increased, until the 15 th of January, when the leg was quite straight. This day, with the assistance of my friends 